\title{
Genistein Effects on Stromal Cells Determines Epithelial Proliferation in Endometrial Co-Cultures
}

\author{
Brante P. Sampey ${ }^{a, b, c}$, Terrence D. Lewis ${ }^{a}$, Claire S. Barbier ${ }^{a}$, Liza Makowski ${ }^{b, c}$, and David \\ G. Kaufman ${ }^{\mathrm{a}, \mathrm{c}}$ \\ aDepartment of Pathology and Laboratory Medicine, University of North Carolina at Chapel Hill, \\ Chapel Hill, North Carolina 27599-7525 \\ bDepartment of Nutrition, University of North Carolina at Chapel Hill, Chapel Hill, North Carolina \\ 27599-7525 \\ 'Lineberger Comprehensive Cancer Center, University of North Carolina at Chapel Hill, Chapel \\ Hill, North Carolina 27599-7525
}

\begin{abstract}
Background-Estrogen is the leading etiologic factor for endometrial cancer. Estrogen-induced proliferation of endometrial epithelial cells normally requires paracrine growth factors produced by stromal cells. Epidemiologic evidence indicates that dietary soy prevents endometrial cancer, and implicates the phytoestrogen genistein in this effect. However, results from previous studies are conflicting regarding the effects of genistein on hormone responsive cancers.
\end{abstract}

\begin{abstract}
Methods-The effects of estrogen and genistein on proliferation of Ishikawa (IK) endometrial adenocarcinoma cells were examined in co-cultures of IK cells with endometrial stromal cells, recapitulating the heterotypic cell-to-cell interactions observed in vivo. The roles of estrogen receptor (ER) $\alpha$ and ER $\beta$ were evaluated using ER $\alpha$ and $E R \beta$ specific agonists. ER activation and cell proliferation in the IK epithelial cells were determined by alkaline phosphatase assay and Coulter counter enumeration, respectively.
\end{abstract}

Results-Both estrogen and genistein increased estrogen receptor-induced gene activity in IK cells over a range of concentrations. Estrogen alone but not genistein increased IK proliferation in co-cultures. When primed by estrogen treatment increasing concentrations of genistein produced a biphasic effect on IK proliferation: $\mathrm{nM}$ concentrations inhibited estrogen-induced proliferation while $\mu \mathrm{M}$ concentrations increased proliferation. Studies with an ER $\beta$-specific agonist produced similar results. Genistein did not influence the effects of estrogen on IK proliferation in monoculture.

Conclusions-Our study indicates that nutritionally relevant concentrations (nM) of genistein inhibit the proliferative effects of estrogen on endometrial adenocarcinoma cells presumably through activation of stromal cell ER $\beta$. We believe that sub-micromolar concentrations of genistein may represent a novel adjuvant for endometrial cancer treatment and prevention.

\footnotetext{
(C) 2010 Elsevier Inc. All rights reserved.

Corresponding Author: David G. Kaufman, M.D., Ph.D., Department of Pathology and Laboratory Medicine, 620 Brinkhous-Bullitt Building, University of North Carolina at Chapel Hill, Chapel Hill, North Carolina 27599-7525.

Publisher's Disclaimer: This is a PDF file of an unedited manuscript that has been accepted for publication. As a service to our customers we are providing this early version of the manuscript. The manuscript will undergo copyediting, typesetting, and review of the resulting proof before it is published in its final citable form. Please note that during the production process errors may be discovered which could affect the content, and all legal disclaimers that apply to the journal pertain.
} 


\section{Keywords}

Genistein; Endometrium; Co-culture; Ishikawa; Stromal cell; Estrogen receptor

\section{INTRODUCTION}

Endometrial cancer is invasive gynecological cancer with the highest incidence in economically advantaged countries (Jemal et al., 2010; American Cancer Society, 2010). Elevated estrogen (17 $\beta$-estradiol) levels, whether from natural, environmental, or therapeutic sources, when not opposed by sufficient progesterone, increases a woman's risk of developing type I (endometrioid) endometrial cancer, the most prevalent form of this disease (Gambacciani et al., 2003; Weiderpass et al., 1999). The relative risk for women who have ever used estrogen replacement therapy (ERT) ranges from 1.4 to 10 when compared to those who have not (Gambacciani et al., 2003; Neves-E-Castro, 2008; Weiderpass et al., 1999). Additional epidemiological factors have been shown to influence the risk of developing endometrial cancer; however, all are directly or indirectly associated with estrogen exposures (Jemal et al., 2010, Amant et al., 2005; Lambe et al., 1999; Parazzini et al., 1994; Kaaks, 2004; Wolin et al., 2010). The addition of progesterone, a hormone that antagonizes effects of estrogen, ameliorates continuous estrogen-stimulated cell proliferation in the endometrium reducing the risk of endometrial cancer (Hulka et al., 1982). These data further emphasize the role of unopposed estrogen on endometrial cancer development. However, the mechanism underlying the malignant transformation of endometrial cells resulting from prolonged estrogen exposure is not thoroughly understood.

Phytoestrogens are plant-derived compounds that resemble the human reproductive hormone estrogen (E2) chemically and have estrogenic or anti-estrogenic activity. Soybeans and soy product are rich in several phytoestrogens and the isoflavone genistein is the major phytoestrogen component in these products. In recent years phytoestrogens like genistein have become a popular dietary supplement used to lessen symptoms of menopause. Concerns have been raised regarding the potential of these products to adversely affect the function of hormone-sensitive tissues and potentiate the development and growth of hormone-sensitive cancers, such as breast, ovarian, and endometrial. Conversely, epidemiologic studies have shown that populations consuming diets rich in soy products have lower incidence rates of these hormone-related cancers (Rozman et al., 2006). Although the anti-cancer mechanisms of soy products are unknown, genistein has been shown to exert diverse biological effects. At low concentrations, genistein is reported to interact with the estrogen receptor (ER), while at high concentrations genistein acts as a tyrosine kinase inhibitor (Peterson, 1995; Wang et al., 1996). Although genistein is able to bind both subtypes of the ER, it has a higher binding affinity for the ER subtype $\beta$ (ER $\beta$ ) (Peterson, 1995). ER $\beta$ activation is thought to antagonize ER $\alpha$ activation through various mechanisms (Saji et al., 2005), and therefore treatment of estrogen-responsive cancers with genistein might antagonize estrogen-induced responses like cell proliferation. However, conflicting evidence indicate that genistein may possess both estrogen-antagonizing and estrogen-potentiating actions (Diel et al., 2004; Diel et al., 2006; Kijkuokool et al., 2006; Mylonas et al., 2003). These controversies extend to the association of phytoestrogen treatments and endometrial cancer. To date there is no consensus on doses of phytoestrogens that may cause adverse effects or the doses that yield optimal benefit to risk ratios, particularly for the purified isoflavone genistein.

Past studies of the effects of estrogen and/or genistein using endometrial cells have been restricted by the lack of an adequate model of hormone responsive endometrium in vitro. To address the role of genistein in an in vitro model system that more accurately represents the 
endometrium in vivo, we have developed a novel co-culture system. This model reconstitutes the humoral heterotypic cell-to-cell interactions mediated by soluble factors that regulate hormonal influences on cell proliferation like those found in the human endometrium in vivo (Arnold et al., 2001; Arnold et al., 2002; Barbier et al., 2005; Barbier et al., 2008). Using this system, previous studies showed that estrogen-induced epithelial cell proliferation and responsiveness to progestins was dependant on the presence of endometrial stromal cells in co-culture with the epithelial cells (Arnold et al., 2001; Arnold et al., 2002; Barbier et al., 2005; Barbier et al., 2008). A similar mechanism involving stromal-epithelial interaction has been demonstrated to be essential for estrogen-induced proliferation in the mouse endometrium (Cooke et al., 1988; Cooke et al., 1997; Cunha et al., 2004). In the study reported here we investigated the effects of nutritionally relevant concentrations of the phytoestrogen genistein on estrogen-induced responses using an Ishikawa (IK) endometrial adenocarcinoma co-culture system. Endpoints investigated included cell proliferation and the alkaline phosphatase (ALPP) assay, a commonly used marker of ER activation and ERdependent differentiation. We evaluated the role of stromal cells in these responses by comparison of monocultures of IK cells to co-cultures of IK cells and endometrial stromal cells. We also explored the roles of ER $\alpha$ and ER $\beta$ using receptor specific agonists to distinguish the mechanisms of action of genistein.

\section{MATERIALS AND METHODS}

\section{Reagents and Cell Culture}

Genistein and $17 \beta$-estradiol were obtained from Sigma (St. Louis, MO). The ER $\alpha$ agonist 4,4', 4"-(4-Propyl-(1H)-pyrazole-1,3,5-triyl)trisphenol (PPT) and the ER $\beta$ agonist diarylpropio-nitrile (DPN) were obtained from TOCRIS (Ellisville, MO). The immortalized noncancerous human endometrial stromal cell line SHT290 (SHT) was developed in our laboratory (Barbier et al., 2005); the human Ishikawa (IK) endometrial adenocarcinoma epithelial cell line (Nishida et al., 1985) was obtained from Dr. Bruce Lessey (Greenville Hospital System University Medical Center, Greenville South Carolina). For $24 \mathrm{hr}$ prior to treatment cell lines were maintained in steroid-free "JAC4" medium consisting of a 1:1 mixture of Ham F12 (GIBCO, Invitrogen Corp, Carlsbad, CA) and M199 basic medium (Sigma) supplemented with $4 \%$ charcoal-stripped fetal bovine serum (Hyclone, Logan UT), $0.25 \%$ ITS+ (insulin-transferin-selenium plus lipoic acid, BD Biosciences, Becton Dickinson, Franklin Lakes, NJ), $0.1 \mathrm{mM}$ phosphorylethanolamine (Sigma) and $2 \mathrm{mM} \mathrm{L-}$ glutamine (GIBCO) and antibiotic/antimycotic solution (GIBCO) diluted to yield 100 units/ $\mathrm{mL}$ penicillin G sodium, $100 \mu \mathrm{g} / \mathrm{mL}$ streptomycin sulfate and $250 \mathrm{ng} / \mathrm{mL}$ amphotericin B. All cultures described in this report were maintained at $37^{\circ} \mathrm{C}$ in a humidified atmosphere of $5 \% \mathrm{CO}_{2}$.

\section{Assessment of Cell Proliferation}

Stromal cells grown in JAC4 medium were seeded in multi-well culture plates (Corning) and Ishikawa adenocarcinoma cells grown in JAC4 were seeded onto cell culture transwell inserts with $0.4 \mu \mathrm{m}$ porosity (Falcon) that were placed into appropriately sized multi-well culture plates. The next day, inserts containing IK cells were placed into the multi-well plate containing SHT cells to create an in vitro model of early type I endometrial cancer. Cocultures were established with an epithelial to stromal cell ratio of 1:5. Inserts were seated in culture wells such that the IK cells were suspended above the adherent stromal cells, allowing for soluble interactions without direct contact between the two cell types. To assess proliferation at the end of the experiment, IK cells were detached from the inserts using a 1:1 mixture of versene (GIBCO) and trypsin-EDTA, thoroughly mixed to obtain single cell suspensions, and enumerated using a Coulter Counter (Beckman Coulter, Inc., Fullerton, CA). 
For assays of the effects of single hormones, co-cultures were first equilibrated in steroidfree JAC4 for $24 \mathrm{hr}$. Thereafter, the co-cultures were treated by addition of $17 \beta$-estradiol ( 0.01 to $1000 \mathrm{nM}$ in $\log _{10}$ increments), genistein $(10,50,100,500$ and $1000 \mathrm{nM}$ ), the ER $\alpha$ specific agonist PPT $(1,10,100$ and $1000 \mathrm{nM})$ or the ER $\beta$ specific agonist DPN $(1,10,100$ and $1000 \mathrm{nM}$ ) into separate co-cultures. Subsequently, the co-cultures were maintained in JAC4 with the same hormone-concentration for 6 days, with replacement of the hormonecontaining media every $48 \mathrm{hr}$ to ensure proper dosing. At the end of this treatment period, the media was removed, the cells washed twice in ice cold Hanks' Buffered Saline Solution (HBSS), and the epithelial cells were trypsinized and counted. Control cultures were treated with only the vehicle used to dissolve hormones.

To assess the effect of genistein on estrogen-driven proliferation, co-cultures acclimated to the serum-free JAC4 media for $24 \mathrm{hr}$ were treated with JAC4 media supplemented with physiologic $(10 \mathrm{nM})$ estrogen for $48 \mathrm{hr}$, after which the medium was changed to JAC4 supplemented with a combination of $10 \mathrm{nM}$ estrogen and increasing concentrations of genistein. The media was changed after $48 \mathrm{hr}$ and the treatment continued for an additional $48 \mathrm{hr}$, resulting in a total of 6 days of treatment as noted previously. Similar studies were conducted to assess the effects of increasing concentrations of the ER $\beta$ agonist DPN on estrogen induced IK proliferation in the co-culture model. Following treatments, IK epithelial cells were washed, trypsinized and counted as described above. Control cultures were treated with only $10 \mathrm{nM}$ estrogen for the duration of the experiment (6 days).

\section{Alkaline Phosphatase Assay to Determine Estrogen Receptor Activation}

Estrogen receptor activation was determined indirectly by assessing estrogen-induced, ERmediated gene activation using an alkaline phosphatase (ALPP)-based bioassay following the protocol developed by Littlefield et al. (1990). Briefly, on the day of the experiment, IK cells were seeded at a density of $7 \times 10^{3}$ cells per well of a 96-well flat bottom micro-titer plate (Corning Inc - Costar, Acton MA) in normal growth medium and allowed to adhere for $24 \mathrm{hr}$. Additionally, SHT stromal cells were seeded onto transwell inserts at a density of $3.5 \times 10^{4}$ and allowed to adhere for $24 \mathrm{hr}$, after which IK cells and SHT cells were brought together to create co-cultures. IK/SHT co-cultures then were treated with vehicle control, estrogen or genistein. After addition of test compounds diluted in growth medium $(200 \mu \mathrm{L} /$ well), cells were incubated for $72 \mathrm{hr}$ at $37^{\circ} \mathrm{C}$ in a humidified atmosphere of $5 \% \mathrm{CO}_{2}$. At the conclusion of the experiment, the stromal cells on the inserts were removed from the cocultures and the medium was removed from the micro-titer plates by inverting and shaking. The adherent IK cells were subsequently washed twice with $0.15 \mathrm{M} \mathrm{NaCl}$ containing $10 \mathrm{mM}$ sodium phosphate $(1 \times \mathrm{PBS}), \mathrm{pH} 7.4$ (GIBCO). Following the last wash, the plates were blotted over clean paper towels, $100 \mu \mathrm{L}$ of methanol (Mallinckrodt Chemicals) was then added to each well, and the plates were incubated at $-70^{\circ} \mathrm{C}$ for $20 \mathrm{~min}$. The plates were removed from $-70^{\circ} \mathrm{C}$ and maintained at room temperature for $5 \mathrm{~min}$. The methanol was removed and $100 \mu \mathrm{L}$ of ALPP substrate, p-nitrophenyl phosphate (pNPP, Sigma), plus 0.24 $\mathrm{mM} \mathrm{MgCl} 2$, and $1 \mathrm{mM}$ diethanolamine (pH 9.8) was added to each well. Plates were protected from light and incubated at room temperature for approximately $3 \mathrm{hr}$. Following incubation, the metabolism of pNPP by the ER-responsive gene product ALPP in IK epithelial cells was assessed by the colorimetric change of the fluid present in each well of the culture dishes as determined by absorption at $405 \mathrm{~nm}$ wavelength in a spectrophotometer (680 Microplate Reader, BioRad).

\section{Statistical Analysis}

Each experimental value was derived from a total of six co-cultures per treatment unless otherwise stated and the mean values and standard deviations of the mean were calculated. Each experiment was repeated at least twice. Data were analyzed using a homoscedastic 
Student T-test. In the Figures data are presented as the mean \pm SD. Values that met the criteria of statistical significance at P $<0.05$ were denoted with an "*” or "\#” and those that were significant at $\mathrm{P}<0.01$ were denoted with a "**” in the Figures.

\section{RESULTS}

\section{Proliferation and Estrogen Receptor Activation by Estrogen or Genistein}

Previous studies have shown that the basal rate of proliferation of endometrial epithelial cells is higher in monoculture than in co-culture (Arnold et al., 2001) indicative of the inhibitory effects of stromal cells on IK cell proliferation. This inhibitory effect of stromal cells was confirmed by the finding that IK cell proliferation also was decreased when they were cultured with medium conditioned by the growth of stromal cell monocultures (Arnold et al., 2002). Additionally, we have shown that the increased IK cell proliferation induced by estrogen in our co-culture model is dependent on the presence of stromal cells, and that this increase in proliferation is higher if stromal factors are permitted to accumulate during the experiment by changing the medium less frequently (Barbier et al., 2005).

To investigate the role of estrogen and genistein on endometrial cell proliferation, we used IK (epithelial) cells in co-cultures with SHT endometrial stromal cells. Expression of both estrogen receptors ER $\alpha$ and ER $\beta$ by the IK cell line was supported by Western blot analysis of total cell lysates (data not shown). Expression of receptors ER $\alpha$ and ER $\beta$ by SHT290 endometrial stromal cells has been reported previously (Barbier et al., 2005). The functional integrity of estrogen receptors in IK cells was confirmed by assessing the effect of estrogen on ER-regulated induction of ALPP activity (Littlefield et al., 1990). In these studies ERmediated induction of ALPP activity was assessed in IK cells in response to a range of concentrations of estrogen $(0.01$ to $1000 \mathrm{nM})$ or genistein $(10$ to $1000 \mathrm{nM})$; control cultures were treated only with vehicle. Both estrogen and genistein treatments produced dosedependent increases in ER activity up to the point of saturation of activity (Figure 1A and $1 \mathrm{~B}$, respectively). Full activation of ER was achieved at $1 \mathrm{nM}$ estrogen while it required 500 $\mathrm{nM}$ of genistein to achieve saturation.

Having shown that IK cells in co-culture were responsive to the estrogen- and genisteininduced ER activation, the effects of graded concentrations of estrogen or genistein on IK cell proliferation were evaluated. Figure 2A demonstrates that estrogen increased IK cell proliferation in a concentration-dependent manner over the range of concentrations shown to mediate ER activation as determined by induction of ALPP activity (Figure 1A). Again, the maximum effect was observed at $1 \mathrm{nM}$ estrogen. In contrast, Figure 2B shows that genistein did not induce IK proliferation in endometrial co-cultures over a range of concentrations (1, 10 and $100 \mathrm{nM}$ ), despite the fact that these concentrations were shown to induce ER activation as assessed by increasing alkaline phosphatase activity in endometrial co-cultures (Figure 1B).

\section{Proliferation and Estrogen-Induced Enzyme Activation by ER $\alpha$ or ER $\beta$ Specific Agonists}

Previous research indicated that estrogen and genistein have different affinities for the two estrogen receptor subtypes (Peterson, 1995). To investigate the basis for the observed differences between estrogen and genistein treatment on ER activity (Figure 1) and on cell proliferation (Figure 2) of IK cells in the co-culture model, we evaluated whether differences in the affinities for ER $\alpha$ or ER $\beta$ reported for estrogen and genistein might be responsible. We performed studies similar to those described above (Figures 1 and 2) but substituted PPT and DPN, which are selective agonists for ER $\alpha$ and ER $\beta$, respectively, for estrogen and genistein. 
Figure 3A shows that the ER $\alpha$ agonist PPT activated ER activity in a dose dependent manner, much like the response shown with increasing estrogen concentrations. Analogous to genistein, the ER $\beta$ agonist DPN increased ER activity in a concentration dependent manner (Figure 3B). Although treatment of endometrial co-cultures with $10 \mathrm{nM}$ PPT (Figure 4 , column 3 ) increased IK cell proliferation, it did not reach the level produced by $10 \mathrm{nM}$ estrogen (Figure 4, column 2). In comparison to the estrogen treatment curve shown in Figure 2, $10 \mathrm{nM}$ genistein produced a level of IK proliferation similar to the level produced by $0.1 \mathrm{nM}$ estrogen. Like genistein, treatment of IK co-cultures with $10 \mathrm{nM}$ DPN did not increase IK proliferation above the control level (Figure 4, column 4).

\section{Effect of Genistein on Estrogen-Induced IK Growth in Co-culture}

Although genistein alone had no proliferative effect on IK cells in our co-culture system (Figure 2B), previous research indicated that genistein could antagonize proliferation induced by estrogen in vivo (Diel et al., 2006). Therefore, IK cells in monoculture or coculture were primed with estrogen $(10 \mathrm{nM})$ for $48 \mathrm{hr}$, followed by co-treatment with estrogen and increasing concentrations of genistein. Treatment of IK monocultures with 10 $\mathrm{nM}$ estrogen produced an increase in IK cell proliferation in monoculture that was unaffected by the addition of 10 or $1000 \mathrm{nM}$ genistein (Figure 5A). In contrast, the combination of estrogen with genistein in the IK co-culture system had a complex effect on epithelial cell proliferation. When compared to treatment of IK co-cultures with estrogen alone (Figure 5B, column 2), increasing concentrations of genistein in the range that is nutritionally relevant (1, 10 and $100 \mathrm{nM}$ ) (Rozman et al., 2006; Cassidy, 2006) decreased estrogen-induced proliferation of IK epithelial cells by approximately $15 \%$ increments for each $\log$ increase of the dose (Figure 5B, columns 3, 4, and 5, respectively). A maximum inhibition of the estrogen-stimulated proliferative response was achieved at $100 \mathrm{nM}$ genistein (a $45 \%$ decrease in estrogen induced proliferation). However, at $1000 \mathrm{nM}$, a superphysiologic concentration when considered in relation to modern Western diets, genistein no longer inhibited estrogen-induced proliferation but potentiated cell proliferation above the level induced by estrogen alone (Figure 5B, column 6).

Genistein has been reported to have a higher affinity for ER $\beta$ than for ER $\alpha$ (Peterson, 1995). In view of this we hypothesized that the concentration-dependent biphasic epithelial proliferative response produced by increasing concentrations of genistein in estrogeninduced co-cultures (Figure 5) might be attributed to the differences in binding of genistein to the two estrogen receptors. We hypothesized further that at low doses, genistein principally affects ER $\beta$-mediated processes whereas at super-physiologic doses genistein might mediate its effects through ER $\alpha$. To test this hypothesis, we investigated the relationship between the concentration of the ER $\beta$-specific agonist DPN and its effect on estrogen-induced proliferation (Figure 6). When compared to estrogen stimulated controls (10 nM, Figure 6, column 1), increasing concentrations of DPN decreased estrogen-induced proliferation by $33 \%$ at $10 \mathrm{nM}$ DPN (Figure 6, column 4); this level of inhibition of proliferation is comparable to that produced by $10 \mathrm{nM}$ genistein (Figure 5B, column 3). At the highest concentration studied $(100 \mathrm{nM})$ there was less inhibition (19\%) of IK cell proliferation by DPN (Figure 6, column 5). This relative increase of proliferation by $100 \mathrm{nM}$ DPN compared to that at $10 \mathrm{nM}$ DPN is similar to the increase of proliferation observed at the highest concentration of genistein $(1000 \mathrm{nM})$ in the estrogen-stimulated model (Figure 5B, column 6).

\section{DISCUSSION}

Numerous studies document that estrogen is the principal etiologic factor for the development of type I endometrial cancer. Soy and soy products are thought to prevent carcinogenesis based on epidemiologic evidence indicating that diets rich in soy are 
protective against hormone-associated cancers such as that of the breast, prostate, colon and endometrium (Rozman et al., 2006). Genistein is the most abundant phytoestrogen in soy. Numerous studies in animals have explored the effects of genistein and soy isolates on breast and prostate cancer in recent years, but the results are conflicting (Kijkuokool et al., 2006; Hillman et al., 2004; Rahal and Simmen, 2010; Harper et al., 2009; Singh-Gupta et al., 2010; Martinez-Montemayer et al., 2010; Raffoul et al., 2007). Few studies, however, have considered effects of these nutritional components on the induction of cancer of the endometrium. Additionally, the mechanisms by which genistein and soy isolates influence cancer development remain obscure, particularly for the endometrium. A better understanding of the effects of genistein and soy products on the endometrium and on the development of endometrial cancer is needed to address its relevance in menopause and for its potential utility as a therapeutic or preventative agent for this form of cancer.

Studies in our laboratory have demonstrated that heterotypic cell-to-cell interactions in cocultures of human endometrial stromal and epithelial cells are necessary for appropriate hormonal and metabolic responses of endometrial epithelial cells in vitro that resemble those found in vivo (Arnold et al., 2001; Arnold et al., 2002; Barbier et al., 2005; Barbier et al., 2008). Therefore, reconstituting a microenvironment in vitro that permits interactions between endometrial stromal cells and endometrial epithelial cells facilitates more accurate investigations into the mechanisms of action of estrogen and/or soy phytoestrogens in endometrium. The aim of this study was to determine whether the presence of the stromal cells influenced the effect of the phytoestrogen genistein on endometrial epithelial cell proliferation when it was used alone or in combination with estrogen stimulation.

Recently, Diel et al. reported anti-estrogenic effects of "low dose" genistein in intact rats and ovariectomized rats co-treated with physiologic doses of estrogen (Diel et al., 2004; Diel et al., 2006), using dosing levels that reflect nutritionally relevant concentrations. A model of the postmenopausal condition (ovariectomized rats) failed to show any notable uterine differences between control and "low dose" genistein-treated animals during chronic exposures (Rimoldi et al., 2007). The lack of an estrogenic effect for genistein in healthy postmenopausal women was established in an NCI-sponsored Phase I trial (Bloedon et al., 2002; Pop et al., 2008), which produced no significant estrogenic, toxic or genotoxic effects. Taken together, these data indicate that genistein alone lacks pro-estrogenic effects on proliferation under both pre- and postmenopausal conditions in rodents and humans, and may antagonize estrogen-induced proliferation in the endometrium.

Estrogen is known to induce proliferation of endometrial cells in vivo, resulting in increased uterine wet weight. Our previous studies using endometrial co-cultures have shown that proliferation and differentiation of the reconstructed endometrial tissue in response to variations of hormone levels is dependent on the presence of stromal cells (Arnold et al., 2001; Arnold et al., 2002; Barbier et al., 2005; Barbier et al., 2008). In the current study we confirmed a concentration-dependent increase in proliferation of endometrial epithelial cells in co-cultures in response to increasing concentrations of estrogen that paralleled an increase of estrogen-induced ER-dependent activation of ALPP gene activity, a well-characterized marker of ER activation (Littlefield et al., 1990). Similar to estrogen, the phytoestrogen genistein increased ER-mediated activation of ALPP activity over a range of physiologic $(\mathrm{nM})$ and super-physiologic $(\mu \mathrm{M})$ concentrations. However a molar concentration of genistein 500 times greater than that of estrogen was required to saturate this activation, reflecting its notably higher affinity for ER $\beta$ compared to ER $\alpha$. Unlike estrogen, genistein alone had no effect on endometrial epithelial cell proliferation in co-cultures even at concentrations shown to activate the ER-mediated ALPP activity. Previous research has shown that both estrogen and genistein produce most of their cellular responses through estrogen-responsive hormone receptor (ER) pathways but differences in the affinities of 
estrogen and genistein for the two ER subtypes (ER $\alpha$ versus ER $\beta$ ) distinguish their potency and their selective biological effects (Peterson, 1995). Therefore we used agonists that are selective for ER $\alpha$ or ER $\beta$ in our co-culture system to determine whether the differences observed in the effects of estrogen and genistein on endometrial cell proliferation resulted from their relative binding efficiencies for ER $\alpha$ versus ER $\beta$.

We found that both the ER $\alpha$ agonist PPT and the ER $\beta$ agonist DPN induced the ERmediated induction of ALPP activity. Like estrogen, PPT also increased cell proliferation in our model system. Similar to the results produced by genistein alone, concentrations of the ER $\beta$ agonist DPN that increased ALPP activity did not increase IK cell proliferation. However a biphasic response of estrogen-stimulated IK cell proliferation was shown in cocultures to increasing concentrations of genistein. At nutritionally relevant concentrations (1 to $100 \mathrm{nM}$ ) genistein inhibited estrogen-induced IK cell proliferation through its preferential activation of ER $\beta$. While genistein selectively acts on the ER $\beta$ at nutritionally-relevant concentrations, at a super-physiologic concentration $(1 \mu \mathrm{M})$ it may also complement estrogen to activate ER $\alpha$. This concentration-dependent effect would result in the loss of the anti-estrogenic effect of genistein on proliferation and induce proliferation above that caused by estrogen alone (Figure 5B, column 6 versus column 2). Our findings suggest that at physiologic concentrations ( 1 to $100 \mathrm{nM}$ ), genistein is preferentially activating ER $\beta$ and that at a super-physiologic concentration $(1000 \mathrm{nM})$ genistein loses its specificity for ER $\beta$ resulting in a loss of its anti-estrogen effect. This premise is supported by our data showing that lower concentrations of the ER $\beta$-specific agonist DPN inhibit estrogen-induced proliferation of IK cells in co-culture while higher concentrations decreased the inhibitory effect (Figure 6). These results collectively support the hypothesis that physiologic genistein predominantly affects the proliferation of IK cells in co-cultures in an ER $\beta$-dependent manner.

Reports in the literature indicate that ER $\beta$ activation in vivo yields an anti-proliferative effect. ER $\beta$ knockout mice display increased uterine cell proliferation and are hyperresponsive to estrogen when compared to the parental wild-type mice (Walker and Korach, 2004). Furthermore, these studies and those of Couse and Korach (Couse and Korach, 1999a; Couse et al., 1999b) emphasize the importance of the ER $\alpha$ subtype in the proliferative responses of the endometrium to estrogen when ER $\beta$ is not operative. The results presented in the current study indicate that concentrations of genistein that are found in serum following typical Western dietary intake of soy products have a distinct antiestrogenic effect on endometrial cell proliferation when administered together with estrogen in co-cultures. In contrast, these same concentrations of genistein increased ER-mediated stimulation of ALPP activity similar to estrogen, but at much higher molar concentrations.

A point to note is that the concentration-dependent effects of genistein on epithelial cell proliferation observed in the present study were found in co-cultures of endometrial epithelial and stromal cells where genistein was present together with estrogen. Our previous studies found that estrogen-induced proliferation of the epithelial cells normally is mediated by paracrine factors secretion by stromal cells. While estrogen promoted an increase in cell proliferation in IK cells in monocultures in the current studies, additions of high or low concentrations of genistein along with estrogen had no discernable effect on IK cell proliferation in monoculture. In contrast, co-cultures showed significant variations in proliferation rates in response to estrogen with various concentrations of genistein. These data indicate that the inhibitory effect of genistein in this co-culture model is mediated by the stromal cells. Since genistein has a selective effect on ER $\beta$ our results suggest that genistein is likely to be functioning via the ER $\beta$ in the stromal cells to counteract estrogeninduced proliferation. At the highest concentration studied, genistein may have exceeded the threshold for activation of ER $\alpha$; the combination of negative (through ER $\beta$ ) and positive 
(through ER $\alpha$ ) regulation reduced inhibition of proliferation. Comparable results were found with ER $\beta$ agonist DPN in co-cultures, though the restoration of estrogen-only proliferation was not complete.

In summary, we found that concentrations of genistein associated with serum levels achievable through dietary intake (i.e. 1 to $100 \mathrm{nM}$ ) are anti-proliferative in estrogenstimulated reconstructed endometrial tissue. Additionally, these effects were not observed in IK cells cultured without stromal cells, indicating that the anti-proliferative response of endometrial epithelial cells is determined by genistein effects on endometrial stromal cells. These results with estrogen and genistein were shown to correlate with specific activation of ER $\alpha$ or ER $\beta$ by chemical agonist PPT and DPN, respectively. The most compelling evidence for the anti-estrogenic, and therefore potentially anti-cancer properties of genistein, were demonstrated by the concentration-dependent inhibition of estrogen-induced IK cell proliferation in the endometrial co-culture model system. These data indicate that nutritionally relevant doses of genistein may have the potential for use as an anti-cancer agent in pre- and peri-menopausal women at risk of estrogen-mediated malignant transformation of the uterus. The results also suggest that micromolar concentrations of genistein may potentiate estrogen-induced stimulation of endometrial proliferation representing a novel risk factor for endometrial cancer. The dichotomous effects of genistein on proliferation that we observed in IK cells in co-cultures, may then explain the dichotomous relationship between genistein and endometrial cancer previously reported in the literature.

\section{Acknowledgments}

We thank W. Todd May for his expertise in optimizing the alkaline phosphatase assay used to assess estrogen receptor activation. This work was supported by grants from the National Institutes of Health [CA096960 to D.G.K. and C.S.B., T32-ES007017 to D.G.K., B.P.S. and T.D.L., T32-CA072319 to B.P.S., F31-GM073349 to T.D.L., a Pilot Project Grant from P30-ES010126 to B.P.S., and a National Center for Minority Health and Health Disparities LRP Award 1 L60 MD002928-01 to B.P.S.].

\section{REFERENCES}

Amant F, Moerman P, Neven P, Timmerman D, Van Limbergen E, Vergote I. Endometrial cancer. Lancet. 2005; 366:491-505. [PubMed: 16084259]

American Cancer Society. Cancer Facts \& Figures 2010. Atlanta, GA: American Cancer Society; 2010.

Arnold JT, Kaufman DG, Seppala M, Lessey BA. Endometrial stromal cells regulate epithelial cell growth in vitro: a new co-culture model. Hum. Reprod. 2001; 16:836-845. [PubMed: 11331626]

Arnold JT, Lessey BA, Seppala M, Kaufman DG. Effect of normal endometrial stroma on growth and differentiation in Ishikawa endometrial adenocarcinoma cells. Cancer Res. 2002; 62:79-88. [PubMed: 11782363]

Barbier CS, Becker KA, Troester MA, Kaufman DG. Expression of exogenous human telomerase in cultures of endometrial stromal cells does not alter their hormone responsiveness. Biol. Reprod. 2005; 73:106-114. [PubMed: 15772261]

Barbier CS, Kloosterboer HJ, Kaufman DG. Effects of tibolone metabolites on human endometrial cell lines in co-culture. Reprod. Sci. 2008; 15:75-82. [PubMed: 18212357]

Bloedon LT, Jeffcoat AR, Lopaczynski W, Schell MJ, Black TM, Dix KJ, Thomas BF, Albright C, Busby MG, Crowell JA, Zeisel SH. Safety and pharmacokinetics of purified soy isoflavones: singledose administration to postmenopausal women. Am. J. Clin. Nutr. 2002; 76:1126-1137. [PubMed: 12399289]

Cassidy A. Factors affecting the bioavailability of soy isoflavones in humans. J. AOAC Int. 2006; 89:1182-1188. [PubMed: 16915862] 
Cooke PS, Buchanan DL, Lubahn DB, Cunha GR. Mechanism of estrogen action: lessons from the estrogen receptor-alpha knockout mouse. Biol. Reprod. 1988; 59:470-475. [PubMed: 9716542]

Cooke PS, Buchanan DL, Young P, Setiawan T, Brody J, Korach KS, Taylor J, Lubahn DB, Cunha GR. Stromal estrogen receptors mediate mitogenic effects of estradiol on uterine epithelium. Proc. Natl. Acad. Sci. U.S.A. 1997; 94:6535-6540. [PubMed: 9177253]

Couse JF, Korach KS. Reproductive phenotypes in the estrogen receptor-alpha knockout mouse. Ann. Endocrinol. (Paris). 1999; 60:143-148. [PubMed: 10456188]

Couse JF, Hewitt SC, Bunch DO, Sar M, Walker VR, Davis BJ, Korach KS. Postnatal sex reversal of the ovaries in mice lacking estrogen receptors alpha and beta. Science. 1999; 286:2328-2331. [PubMed: 10600740]

Cunha GR, Cooke PS, Kurita T. Role of stromal-epithelial interactions in hormonal responses. Arch. Histol. Cytol. 2004; 67:417-434. [PubMed: 15781983]

Cushing KL, Weiss NS, Voigt LF, McKnight B, Beresford SA. Risk of endometrial cancer in relation to use of low-dose, unopposed estrogens. Obstet. Gynecol. 1998; 91:35-39. [PubMed: 9464717]

Diel P, Geis RB, Caldarelli A, Schmidt S, Leschowsky UL, Voss A, Vollmer G. The differential ability of the phytoestrogen genistein and of estradiol to induce uterine weight and proliferation in the rat is associated with a substance specific modulation of uterine gene expression. Mol. Cell. Endocrinol. 2004; 221:21-32. [PubMed: 15223129]

Diel P, Hertrampf T, Seibel J, Laudenbach-Leschowsky U, Kolba S, Vollmer G. Combinatorial effects of the phytoestrogen genistein and of estradiol in uterus and liver of female Wistar rats. J. Steroid Biochem. Mol. Biol. 2006; 102:60-70. [PubMed: 17049845]

Gambacciani M, Monteleone P, Sacco A, Genazzani AR. Hormone replacement therapy and endometrial, ovarian and colorectal cancer. Best Practice \& Res. Clin. Endocrinol. \& Metab. 2003; 17:139-147.

Harper CE, Cook LM, Patel BB, Wang J, Eltoum IA, Arabshahi A, Shirai T, Lamartiniere CA. Genistein and resveratrol, alone and in combination, suppress prostate cancer in SV-40 tag rats. Prostate 1. 2009:1668-1682.

Hillman GG, Wang Y, Kucuk O, Che M, Doerge DR, Yudelev M, Joiner MC, Marples B, Forman JD, Sarkar FH. Genistein potentiates inhibition of tumor growth by radiation in a prostate cancer orthotopic model. Mol. Cancer Ther. 2004; 3:1271-1279. [PubMed: 15486194]

Hulka BS, Chambless LE, Kaufman DG, Fowler WC Jr, Greenberg BG. Protection against endometrial carcinoma by combination-product oral contraceptives. JAMA. 1982; 247:475-477. [PubMed: 7033575]

Jemal A, Seigel R, Xu J, Ward E. Cancer statistics, 2010. CA Cancer J. Clin. 2010; 60:277-300. [PubMed: 20610543]

Kaaks R. Nutrition, insulin, IGF-1 metabolism and cancer risk: a summary of epidemiological evidence. Novartis Found. Symp. 2004; 262:247-260. discussion 260-268. [PubMed: 15562834]

Kijkuokool P, Parhar IS, Malaivijitnond S. Genistein enhances N-nitrosomethylurea-induced rat mammary tumorigenesis. Cancer Lett. 2006; 242:53-59. [PubMed: 16338062]

Lambe M, Wuu J, Weiderpass E, Hsieh CC. Childbearing at older age and endometrial cancer risk (Sweden). Cancer Causes Control. 1999; 10:43-49. [PubMed: 10334641]

Littlefield BA, Gurpide E, Markiewicz L, McKinley B, Hochberg RB. A simple and sensitive microtiter plate estrogen bioassay based on stimulation of alkaline phosphatase in Ishikawa cells: estrogenic action of delta 5 adrenal steroids. Endocrinology. 1990; 127:2757-2762. [PubMed: 2249627]

Martỉnez-Montemayer MM, Otero-Franqui E, Martinez J, De La Mota-Peynado A, Cubano LA, Dharmawardhane S. Individual and combined soy isoflavones exert differential effects on metastatic cancer progression. Clin. Exp. Metastasis. 2010; 27:465-480. [PubMed: 20517637]

Mylonas I, Jeschke U, Makovitzky J, Winkler L, Richter DU, Friese K, Briese V. Immunohistochemical expression of steroid receptors and glycodelin A in isolated proliferative human endometrial glandular cells after stimulation with tamoxifen and phytoestrogens (genistein and daidzein). Anticancer Res. 2003; 23:1119-1125. [PubMed: 12820358]

Neves-E-Castro M. Association of ovarian and uterine cancers with postmenopausal hormonal treatments. Clin. Obstet. Gynecol. 2008; 51:607-617. [PubMed: 18677154] 
Nishida M, Kasahara K, Kaneko M, Iwasaki H, Hayashi K. Establishment of a new human endometrial adenocarcinoma cell line, Ishikawa cells, containing estrogen and progesterone receptors. Nippon Sanka Fujinka Gakkai Zasshi. 1985; 37:1103-1111. [PubMed: 4031568]

Parazzini F, La Vecchia C, Moroni S, Chatenoud L, Ricci E. Family history and the risk of endometrial cancer. Int. J. Cancer. 1994; 59:460-462. [PubMed: 7960212]

Peterson G. Evaluation of the biochemical targets of genistein in tumor cells. J. Nutr. 1995; 125(3 Suppl):784S-789S. [PubMed: 7884565]

Pop EA, Fischer LM, Coan AD, Gitzinger M, Nakamura J, Zeisel SH. Effects of a high daily dose of soy isoflavones on DNA damage, apoptosis, and estrogenic outcomes in healthy postmenopausal women: a phase I clinical trial. Menopause. 2008; 15:684-692. [PubMed: 18446090]

Raffoul JJ, Banerjee S, Che M, Knoll ZE, Doerge DR, Abrams J, Kucuk O, Sarkar FH, Hillman GG. Soy isoflavones enhance radiotherapy in a metastatic prostate cancer model. Int. J. Cancer. 2007; 120:2491-2498. [PubMed: 17304503]

Rahal OM, Simmen CM. PTEN and p53 cross-regulation induced by soy isoflavone genistein promotes mammary epithelial cell cycle arrest and lobuloalveolar differentiation. Carcinogenesis. 2010; 31:1491-1500. [PubMed: 20554748]

Rimoldi G, Christoffel J, Seidlova-Wuttke D, Jarry H, Wuttke W. Effects of chronic genistein treatment in mammary gland, uterus, and vagina. Environ. Health Perspect. 2007; 115 Suppl 1:6268. [PubMed: 18174952]

Rozman KK, Bhatia J, Calafat AM, Chambers C, Culty M, Etzel RA, Culty M, Etzel RA, Flaws JA, Hansen DK, Hoyer PB, Jeffery EH, Kesner JS, Marty S, Thomas JA, Umbach Dl. NTP-CERHR expert panel report on the reproductive and developmental toxicity of genistein. Birth Defects Res. B. Dev. Reprod. Toxicol. 2006; 77:485-638. [PubMed: 17186522]

Saji S, Hirose M, Toi M. Clinical significance of estrogen receptor beta in breast cancer. Cancer Chemother. Pharmacol. 2005; 56 Suppl 1:21-26. [PubMed: 16273360]

Singh-Gupta V, Zhang H, Yunker CK, Ahmad Z, Zwier D, Sarkar FH, Hillman GG. Daidzein Effect on Hormone Refractory Prostate Cancer In Vitro and In Vivo Compared to Genistein and Soy Extract: Potentiation of Radiotherapy. Pharm. Res. 2010; 27:1115-1127. [PubMed: 20309614]

Wang TT, Sathyamoorthy N, Phang JM. Molecular effects of genistein on estrogen receptor mediated pathways. Carcinogenesis. 1996; 17:271-275. [PubMed: 8625449]

Walker VR, Korach KS. Estrogen receptor knockout mice as a model for endocrine research. ILAR J. 2004; 45:455-461. [PubMed: 15454684]

Weiderpass E, Adami HO, Baron JA, Magnusson C, Bergstrom R, Lindgren A, Correia N, Persson I. Risk of endometrial cancer following estrogen replacement with and without progestins. J. Natl. Cancer Inst. 1999; 91:1131-1137. [PubMed: 10393721]

Wolin KY, Carson K, Colditz GA. Obesity and cancer. Oncologist. 2010; 15:556-565. [PubMed: 20507889] 
A

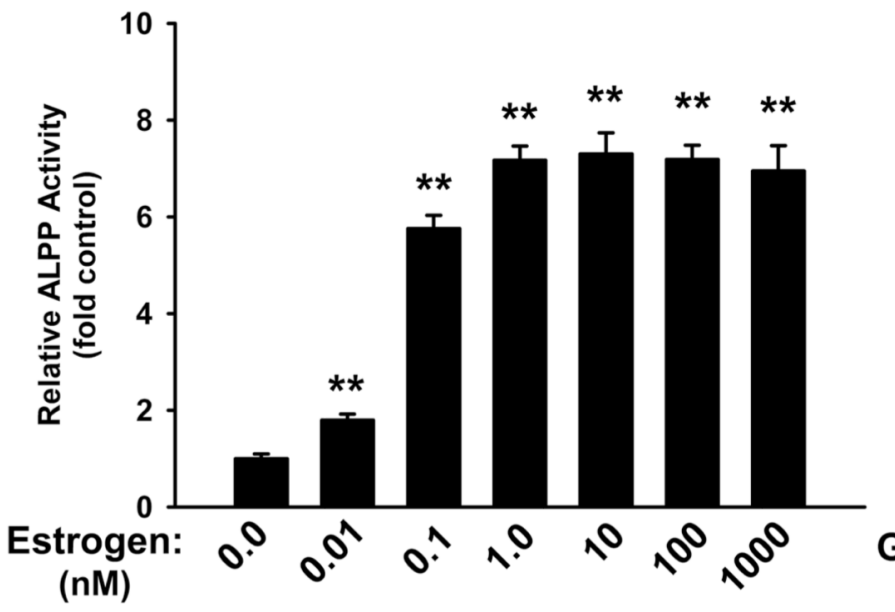

B

GENISTEIN

Figure 1. Estrogen and genistein induction of ER-regulated alkaline phosphatase activity in IK cells in endometrial co-cultures

A. Estrogen activates the estrogen receptor in endometrial epithelial cells co-cultured with endometrial stromal cells as determined by measuring alkaline phosphatase activity, a known gene product of estrogen receptor activation. Column $1=$ vehicle control, columns 2 through 7 are estrogen treatments at $0.01,0.1,1.0,10,100,1000 \mathrm{nM}$. Results measured by the ordinate are the ratio of the estrogen treated co-cultures to the untreated vehicle controls, expressed as fold-increases. B. Genistein activates the estrogen receptor over a range of physiologic concentrations; column $1=$ vehicle control, columns 2 through 6 are genistein treatments at 10,50,100, 500 and $1000 \mathrm{nM}$ genistein. The height of the columns represents the average of samples studied $(\mathrm{N} \geq 8)$. $* * \mathrm{P}<0.01$. 
A

ESTROGEN

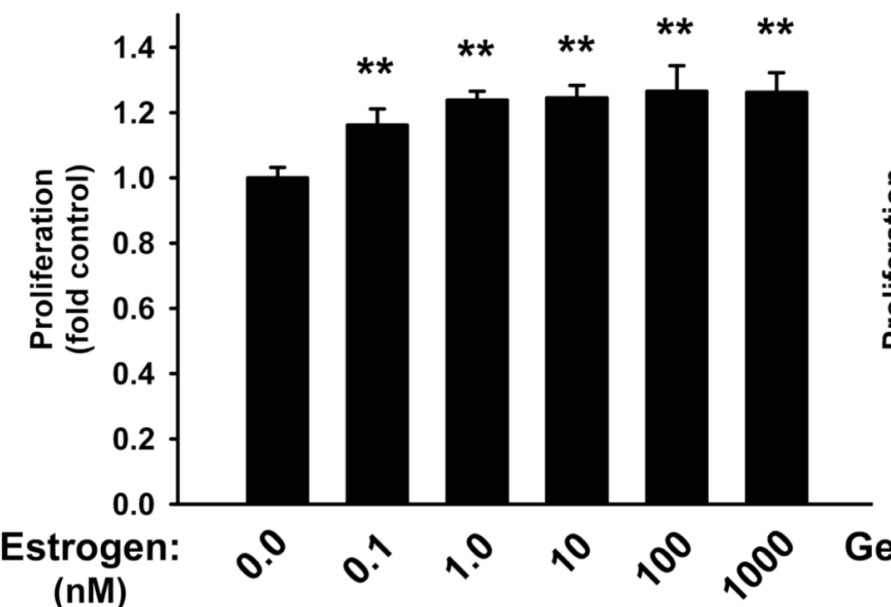

$\mathbf{B}$

GENISTEIN

Figure 2. Effects of estrogen and genistein on epithelial cell proliferation in endometrial cocultures

A. Estrogen increases endometrial epithelial cell proliferation in co-culture in a dose dependent manner; column 1 = vehicle control, columns $2-6=0.1,1.0,10,100$ and 1000 $\mathrm{nM}$ estrogen. Results measured by the ordinate are the ratio of the estrogen treated cocultures to the untreated vehicle controls, expressed as fold-increases. B. Genistein fails to induce endometrial epithelial proliferation in co-culture at concentrations shown to activate the estrogen receptor (Figure 1B); column 1 = vehicle control, columns $2-4=1.0,10$ and $100 \mathrm{nM}$ genistein. The height of the columns represents the average of samples studied $(\mathrm{N} \geq$ 4). $* * \mathrm{P}<0.01$. 
A

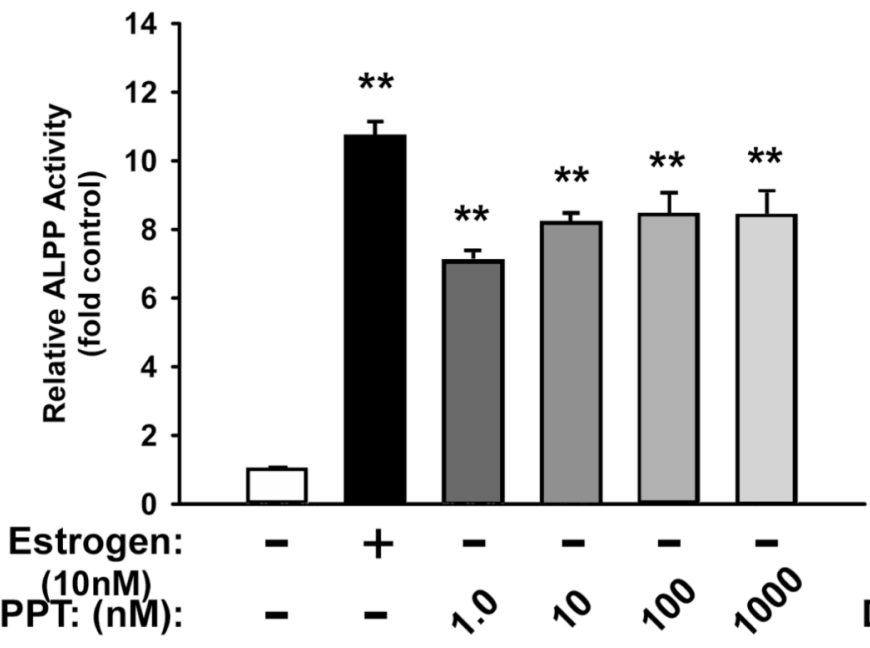

B

DPN: ERß AGONIST

Figure 3. Effects of estrogen receptor $\alpha$ - or $\beta$-specific agonists (PPT and DPN) on ER-regulated alkaline phosphatase activity in endometrial co-cultures

A) The ER $\alpha$-specific agonist PPT stimulates ER-regulated alkaline phosphatase activity over a concentration range of 1.0 to $1000 \mathrm{nM}$ (columns 3 to 6) when compared to vehicle control (column 1), but does not achieve an activity equivalent to that of $10 \mathrm{nM}$ estrogen (column 2). Results measured by the ordinate are the ratios of the estrogen or PPT-treated co-cultures to the untreated vehicle controls, expressed as fold-increases. B) The ER $\beta$-specific agonist DPN stimulates ER-regulated alkaline phosphatase activity at concentrations ranging from 10 to $1000 \mathrm{nM}$ (columns 4 to 6) when compared to vehicle control (column 1), but not at 1.0 $\mathrm{nM}$ (column 3). DPN also does not achieve an activity equivalent to that stimulated by 10 $\mathrm{nM}$ estrogen (10 nM, column 2) at the highest concentration tested (column 6). Results measured by the ordinate are the ratios of the estrogen or PPT-treated co-cultures to the untreated vehicle controls, expressed as fold-increases. The height of the columns represents the average of the samples studied $(\mathrm{N} \geq 11)$. $* * \mathrm{P}<0.01$ versus vehicle control. 


\section{ESTROGEN / PPT / DPN: PROLIFERATION}

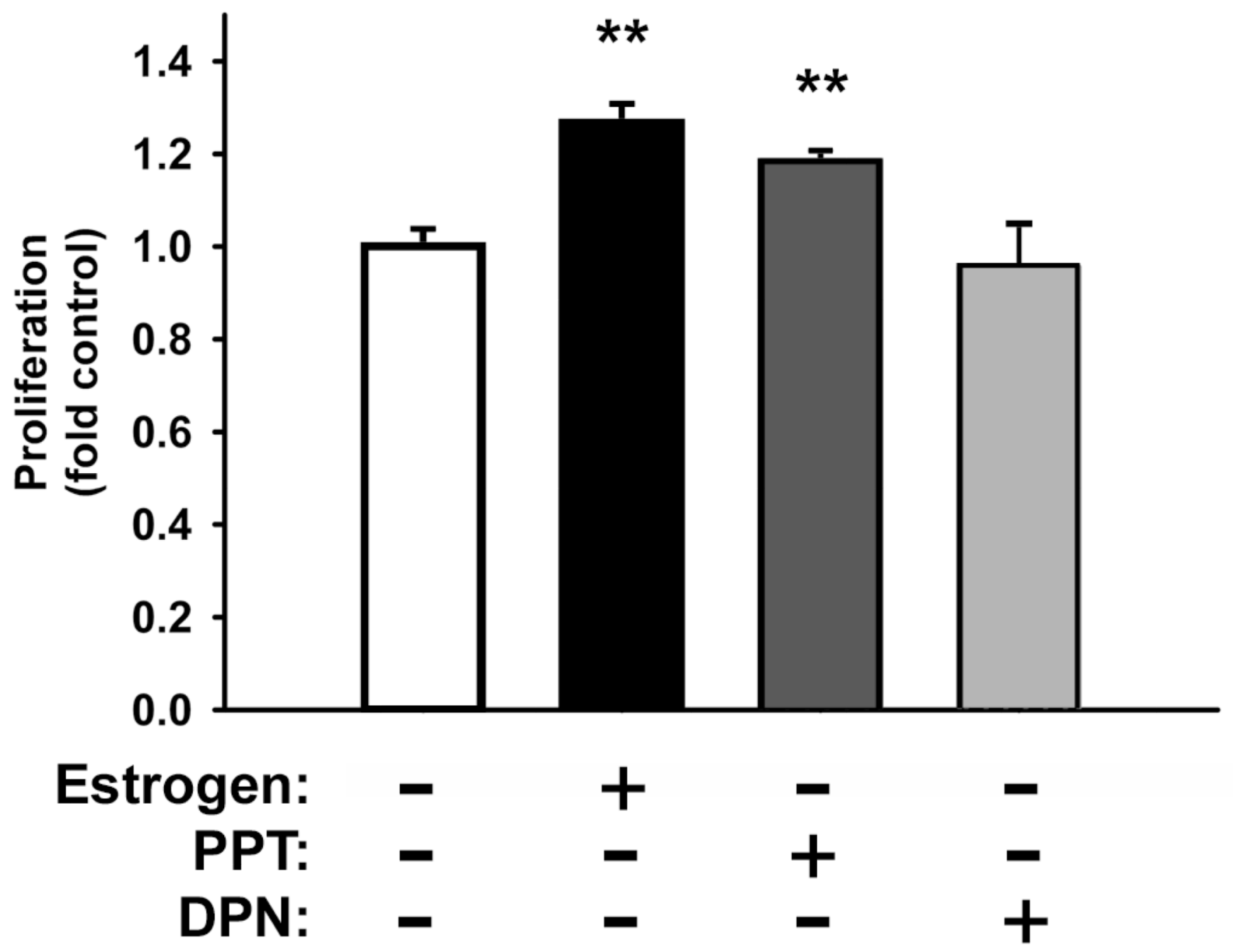

Figure 4. Effects of estrogen receptor $\alpha$ - or $\beta$-specific agonists (PPT and DPN) on epithelial cell proliferation in endometrial co-cultures

Estrogen (10 nM, column 2) and the ER $\alpha$-agonist PPT (10 nM, column 3) both increased endometrial epithelial cell proliferation in co-cultures significantly when compared to the vehicle control (column 1). The ER $\beta$-agonist DPN (10 nM, column 4) had no effect on endometrial epithelial cell proliferation. Results measured by the ordinate are the ratios of the estrogen or receptor-specific agonists to the untreated vehicle controls, expressed as fold-increases. Data shown represents the average of the samples studied $(\mathrm{N} \geq 3)$. **P < 0.01 . 


\section{A MONOCULTURE}
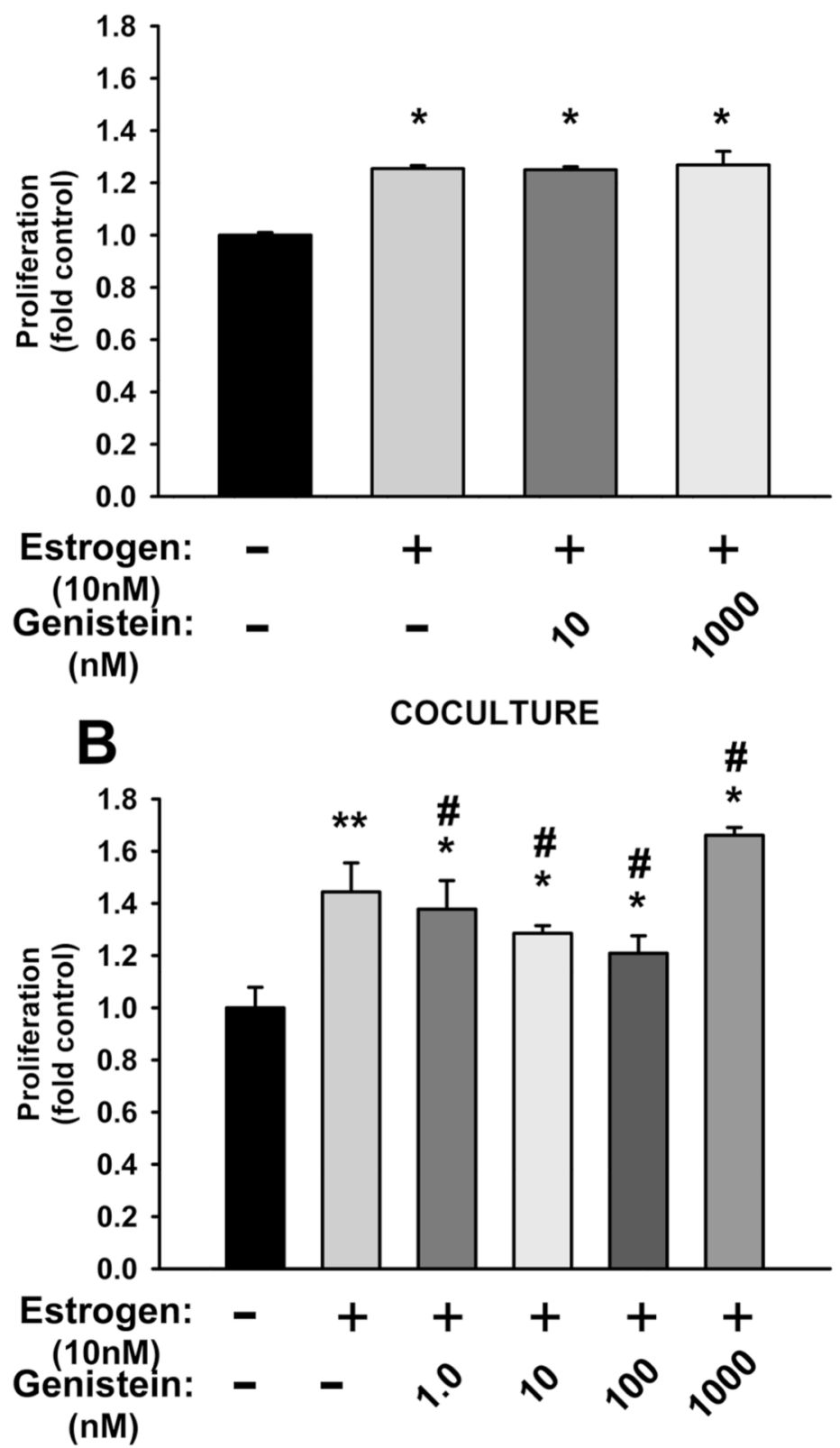

Figure 5. Effects of estrogen and genistein co-treatment on epithelial cell proliferation in monocultured versus co-cultured endometrial epithelial cells

A. In monocultures, estrogen induces a modest but significant increase in IK cell proliferation (column $2=10 \mathrm{nM}$ estrogen). Concurrent treatment with 10 or $1000 \mathrm{nM}$ genistein (column $3=10 \mathrm{nM}$ estrogen $+10 \mathrm{nM}$ genistein; column $4=10 \mathrm{nM}$ estrogen + $1000 \mathrm{nM}$ genistein) did not change IK cell proliferation. Results are presented as the ratios of the estrogen or estrogen plus genistein to the untreated vehicle controls (column 1) shown as fold-increases (ordinate). B. In co-cultures, genistein inhibits estrogen induced IK proliferation (10 $\mathrm{nM}$ estrogen, column 2) in a biphasic manner. Physiologic concentrations of genistein (1 to $100 \mathrm{nM}$ ) decreased estrogen-induced proliferation by $15 \%, 30 \%$ and $45 \%$ 
at $1.0 \mathrm{nM}$ (column 3), $10 \mathrm{nM}$ (column 4) and $100 \mathrm{nM}$ (column 5), respectively. At a higher concentration $(1000 \mathrm{nM})$, genistein significantly increases the proliferative effects of $10 \mathrm{nM}$ estrogen (column 6) above that of estrogen alone (column 2). Results are presented as the ratios of the estrogen or estrogen/genistein combinations to the untreated vehicle controls (column 1) and are shown as fold-increases (ordinate). Data shown represent the average of the samples studied $(\mathrm{N} \geq 3)$. $* \mathrm{P}<0.05$ versus vehicle control, \# $\mathrm{P}<0.05$ versus estrogentreated sample; $* * \mathrm{P}<0.01$ versus vehicle control. 


\section{ESTROGEN/DPN CO-TREATMENT}

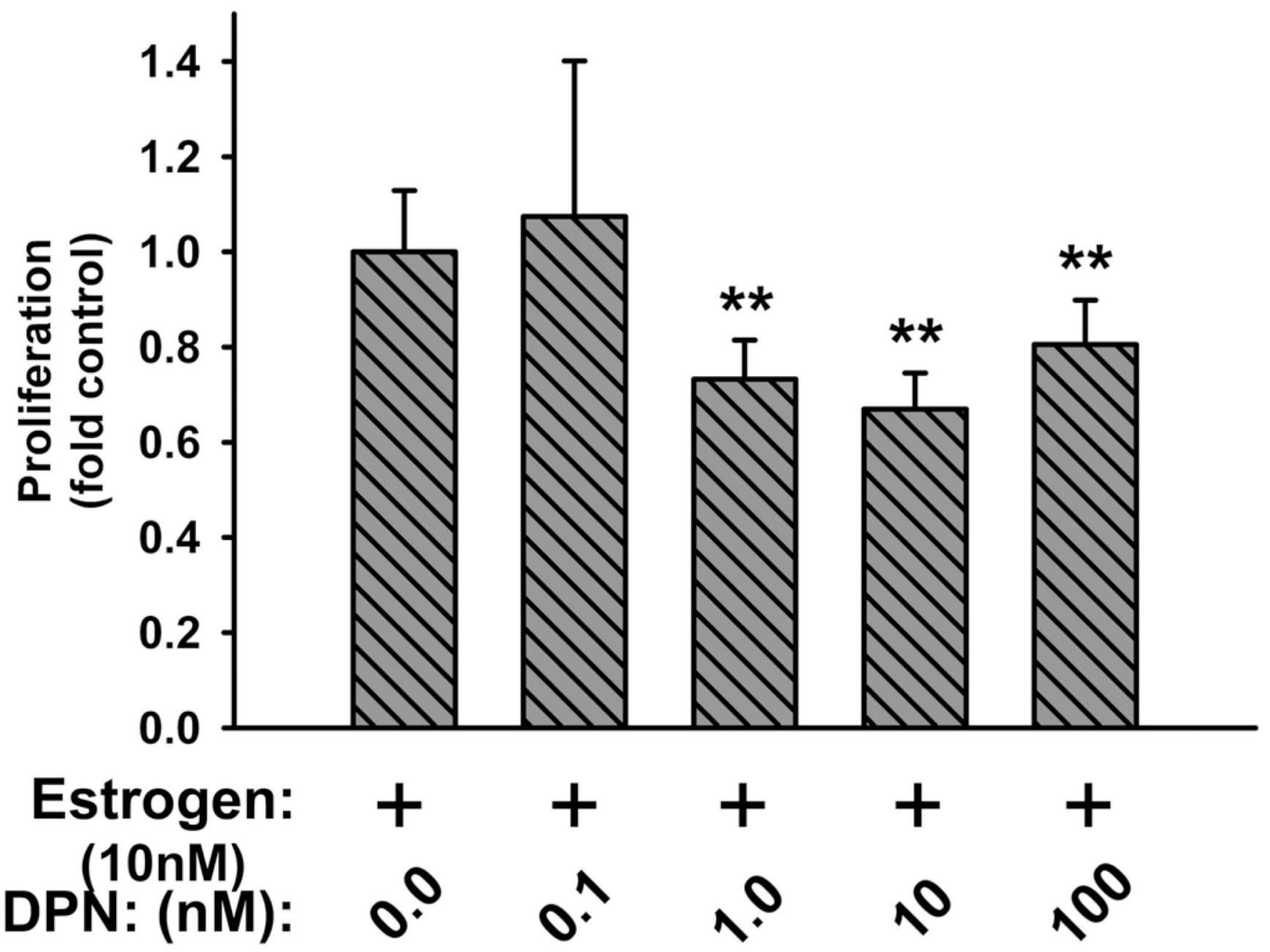

Figure 6. Effect of the ERB-agonist DPN on epithelial cell proliferation of IK cells in endometrial co-culture

The estrogen receptor (ER)- $\beta$ subtype specific agonist DPN inhibited estrogen-induced IK proliferation in co-culture over a range of concentrations similar to that produced by increasing concentrations of genistein. IK co-cultures were treated with $10 \mathrm{nM}$ estrogen (column 1) or increasing concentrations of DPN (0.1, 1.0, 10 and $100 \mathrm{nM}$; columns 2 - 5, respectively). Inhibition of estrogen induced proliferation was maximal at a concentration of $10 \mathrm{nM}$ DPN, above which DPN became less inhibitory. Results are presented as the ratios of the estrogen/DPN combinations to the $10 \mathrm{nM}$ estrogen-alone control (column 1) and are shown as fold-increases (ordinate). $* * \mathrm{P}<0.01$. 